\title{
Retraction
}

The article titled, "Observations on radiological correction of acetabular dysplasia by Dega transiliac osteotomy", published in the International Journal of Research in Medical Sciences, Volume 5, Issue 5, 2017, Pages 1991-1997, DOI: http://dx.doi.org/10.18203/2320-6012.ijrms20171831 is being retracted on authors request. The authors of this article want to redo the calculations with a follow up of more than 4 years so that the results are more conclusive of the effectiveness of the procedures. Since majority of patients are of developmental dysplasia of hip (DDH) the results are not representative of the effectiveness of the procedure in other disorders associated with acetabular dysplasia. Either the study has to be restricted to the patients of DDH or need to add more patients from other pathologies to make it a more conclusive study regarding other causes of acetabular dysplasia. The authors want to add some more criteria for assessment of acetabular dysplasia so that the effectiveness of the procedure can be gauged in a better way. 


\title{
Original Research Article
}

\section{Observations on radiological correction of acetabular dysplasia by Dega transiliac osteotomy}

\author{
Wazir Fahad Jan', Sanjay Sarup ${ }^{1}$, Mohd Yahya Dar², Alamgir Jahan ${ }^{3}$, Ovais Nazir Khan ${ }^{4}$
}

${ }^{1}$ Department of Orthopedics, Artemis Health Institute, Gurgaon, Haryana, India

${ }^{2}$ Department of Orthopedics, SHKM, GMC, Nalhar, Haryana, India

${ }^{3}$ Department of Orthopedics, GMC, Jammu, Jammu and Kashmir, India

${ }^{4}$ Department of Anaesthesia, Artemis Health Institute, Gurgaon, Haryana, India

Received: 03 March 2017

Revised: 10 March 2017

Accepted: 01 April 2017

\section{*Correspondence:}

Dr. Wazir Fahad Jan,

E-mail: fahadwzr@yahoo.com

Copyright: () the author(s), publisher and licensee Medip Academy. This is an open-access article distributed under the terms of the Creative Commons Attribution Non-Commercial License, which permits unrestricted non-commercial use, distribution, and reproduction in any medium, provided the original work is properly cited.

\section{ABSTRACT}

Background: Several osteotomies have been described for the correction of acetabular dysplasia associated with variable outcomes. The purpose of our study was to evaluate the effect of Dega transiliac osteotomy in radiological correction of acetabular dysplasia by assessing the change in various radiological parameters from preoperative period to postoperative period and at a follow up of two years.

Methods: This was a prospective obseryational study conducted on 35 patients of either sex, in the age range of 18 months to 8 years, presenting to the paediatric orthopaedic OPD, of Artemis Health Institute, Gurgaon, Haryana, India between January 2012 and September 2014 in whom a diagnosis of acetabular dysplasia was made. All the patients underwent Dega transiliac osteotomy and the effectiveness of this osteotomy in the correction of acetabular dysplasia was assessed by measuring various radiological parameters preoperatively, postoperatively, and at a follow up of two years. The various radiological parameters included acetabular index (AI), centre edge angle of wiberg (CEAW), reimer's extrusion index (REI) and the shenton's line (SL).

Results: In present study sample of 35 cases, 29 had DDH, 4 were secondary to cerebral palsy and 2 had developed dysplasia following septic arthritis of the hip. The sex distribution showed 19 females and 16 male patients. All the patients underwent Dega transiliac osteotomy at a mean age of $42.94 \pm 21.68$ months. The mean value of AI improved from $42.43 \pm 4.77$ degrees in preoperative period to $19.86 \pm 2.45$ degrees at follow up. The mean value of CEAW improved from - 32.49 \pm 21.60 degrees in preoperative period to $32.06 \pm 5.48$ degrees at follow up. The mean value of REI, improved from $91.06 \pm 21.43 \%$ in preoperative period to $0.29 \pm 1.18 \%$ at follow up. The SL was broken in all the 35 patients preoperatively, while at follow up it was continuous in all the patients. These changes in all the four parameters were statistically highly significant ( $\mathrm{p}$ value $<0.001$ ).

Conclusions: Thus results of present study demonstrate that Dega osteotomy is a safe, effective and versatile surgical procedure for the treatment of acetabular dysplasia secondary to DDH and other disorders. Since the majority of the patients included in this study had the diagnosis of DDH, the results of this study are more representative of dysplasia associated with DDH.

Keywords: Acetabular dysplasia, Cerebral palsy, Dega osteotomy, Developmental dysplasia of hip 


\section{INTRODUCTION}

Acetabular dysplasia is a condition defined by the inadequate development of an individual's acetabulum. The resulting acetabulum is shallow and disc shaped rather than the normal cup shaped. The roof of the acetabulum is obliquely inclined outward, rather than having the normal horizontal orientation. Because of these abnormalities, the superior and usually anterior femoral head are incompletely covered by this dysplastic acetabulum resulting in an abnormally high stress on the outer edge of the acetabulum, which leads to degeneration of the articular cartilage and arthritic changes. Patients with acetabular dysplasia, who have developed symptoms around the age of 20 , rarely get beyond their early thirties without requiring total hip arthroplasty. ${ }^{1}$

Acetabular dysplasia is seen in developmental dysplasia of hip (DDH). A variety of other disorders including cerebral palsy, infection, trauma or Perthes disease may also present with acetabular dysplasia. It is characterized by certain typical morphological features as described by Salter who stated that acetabular dyplasia was secondary to malposition of the hip and characterized by a maloriented and hypo-plastic acetabulum. ${ }^{2}$ Wedge described certain other characteristics associated with acetabular dysplasia which include a combination of mal-direction, marginal erosion, torsion, hypoplasia (localized or global deficiency), abnormal shape and decreased surface area of the acetabulum available for load bearing articular cartilage to articulate with the femoral head. ${ }^{3}$

Management of DDH and other disorders with acetabular dysplasia upto 18 months of age is primarily conservative with use of Pavlik Harness and closed reduction. Surgical procedures are primarily done after 18 months of age. Various surgical techniques have been described to treat acetabular dysplasia. These surgical procedures have been divided into those which redirect the acetabulum such as the Salter innominate osteotomy, Sutherland double innominate osteotomy, hip reorientation procedures such as Steel triple and Tonnis et al procedures, and the acetabuloplasty procedures such as the Pemberton and San Diego osteotomies which address both the hypoplasia and malorientation by reshaping and improving the volume of acetabulum and there is no compromise in posterior coverage. ${ }^{4-11}$

In 1969, Dega described a transiliac osteotomy for the treatment of residual acetabular dysplasia secondary to congenital hip dysplasia and dislocation. ${ }^{12} \mathrm{He}$ described it as an incomplete transiliac osteotomy of the anterior and middle portions of the inner cortex of the ilium, leaving an intact hinge posteriorly consisting of the intact posteromedial iliac cortex and sciatic notch.

This osteotomy takes advantage of the inherent flexibility of the triradiate cartilage and the surrounding bone in the pelvis of young children to reshape the acetabulum. This osteotomy has been found to provide good acetabular coverage in children with DDH. In the present study, we used Dega osteotomy to evaluate correction of various radiological parameters in patients with acetabular dysplasia due to DDH and other disorders by measuring the parameters preoperatively, postoperatively and at a follow up of 2 years. The various radiological parameters included Acetabular Index, Centre Edge Angle of Wiberg Reimer's Extrusion Index and the Shenton's line. ${ }^{13-18}$

\section{METHODS}

After approval by the institutional ethics committee and informed written consent, data was collected regarding measurement of radiographic parameters preoperatively, postoperatively, and at follow up. This was a prospective observational study conducted on 35 patients of either sex, in the age range of 18 months to 8 years, presenting to the Paediatric Orthopaedic OPD, of Artemis Health Institute, Gurgaon, Haryana, India between January 2012 and September 2014 in whom a diagnosis of acetabular dysplasia was made.

The patients with acetabular dysplasia secondary to $\mathrm{DDH}$, septic arthritis and neuromuscular disorders like cerebral palsy were included in the study. The patients excluded included those with low grade acetabular dysplasia (that is acetabular index of, 30 degrees to 34 degrees, and an intact Shenton line), severely dysplastic small acetabulum and unusually large femoral head, with active infections in the hip joint and those with residual acetabular dysplasia in patients previously treated by pelvic osteotomy.

All patients in this study underwent antero-posterior radiographs of pelvis 24 hours prior to surgery carried out in a standard supine position, with the cathode ray tube 30 inches above the centre of the symphysis pubis.

\section{Surgical technique}

After administration of general anaesthesia, the patient was placed in supine position with the involved hip tilted up approximately 30 to 40 degrees by a bump placed at the sacrum level. The Somerville anterior approach was used. An anterior bikini incision was made 1 to $2 \mathrm{cms}$ below the level of the anterior superior iliac spine.

The incision was given in a straight line, running from the tip of the greater trochanter at its lateral limit, passing 1 to $2 \mathrm{cms}$ below the level of the anterior superior iliac spine to the medial border of Sartorius, in an oblique fashion. The rest of the dissection followed the Smith Peterson interval. The iliac crest was now exposed and the apophysis was split longitudinally with a No. 15 blade through its entire anterior one third and turned down along with the periosteum of the outer table of the ileum.

Sub-periosteal elevation of hip abductor musculature was carried out to expose the lateral wall of the ilium down to 
the capsule of the hip. The dissection was completed with exposure of the sciatic notch. Next, the Dega osteotomy was performed. Marking of the orientation of the osteotomy was done on the lateral cortex of the ilium. The direction of the osteotomy was curvilinear when viewed from the lateral cortex, starting just above the anterior inferior iliac spine, curving gently cephalad and posteriorly to reach a point superior to the midpoint of the acetabulum, and then continuing posteriorly to end approximately 1 to $1.5 \mathrm{~cm}$ in front of the sciatic notch.

A guide-wire was inserted under fluoroscopic control at the most cephalad point of the curvilinear marking line, directed caudally and medially. A straight $1 / 4$-inch or $1 / 2-$ inch osteotome was used to make the bone cut, which extended obliquely medially and inferiorly, paralleling the guidewire to exit through the inner cortex just above the iliopubic and ilioischial limbs of the triradiate cartilage (Figure 1).

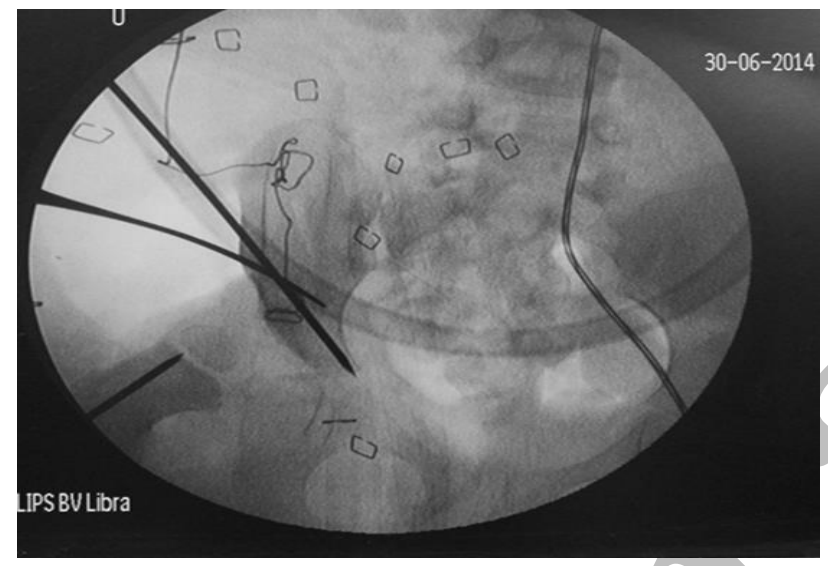

Figure 1: Intraoperative fluoscopic view of Dega osteotomy being done.

A $1 / 2$-inch osteotome was used to gently lever open the osteotomy site either anteriorly or laterally in a controlled manner. The osteotomy site was kept open by inserting one or two correctly sized bone grafts which were obtained from femoral shaft in the patients in whom concomitant femoral shortening was carried out. In 2 cases with post-septic acetabular dysplasia cases, femoral shortening was not carried out. Here, synthetic tricalcium phosphate grafts were used to keep the osteotomies open.

Fluoroscopy was carried out after insertion of the graft to check the improvement in acetabular index. In cases of DDH, clearance of the hip joint was required. This was done by arthroscopic clearance of the hip joint using radiofrequency probes. In all cases of DDH and cerebral palsy (33 patients), femoral shortening and varus derotation osteotomy was carried out.

The femoral procedure was accompanied by plate fixation. After closure, a double spica cast was applied with the hip in neutral rotation, 95 degrees of flexion and
40 to 45 degrees of abduction (Human position or Lorenz position). Standard postoperative care pathway was followed for these children. After 48 hours postoperative radiograph was taken. At 3 weeks the hip spica was changed in all the cases. The second hip spica was kept for 9-10 weeks.

At the end of this period, the cast was removed and hip abduction brace was applied. The parents were instructed on exercises to be carried out at home which included passive abduction range, active assisted and active hip abduction, and weight bearing on a walking frame. The hip abduction brace was maintained for 6 months or longer, depending upon the degree of residual dysplasia seen on radiographs. Radiographs were taken at 2 years postoperatively, and all radiographs were subjected to analysis.

\section{Statistical methods}

Descriptive statistics were analyzed with SPSS version 17.0 software. Continuous variables were presented as mean (SD). Categorical variables were expressed as frequencies and percentages. Nominal categorical data between the groups was compared using Chi-squared test or Fisher's exact test as appropriate. A p value less than 0.05 was taken to indicate a significant difference.

\section{RESULTS}

In present study, the age of the 35 patients ranged from 18 months to 8 years (96 months) with a mean age of the patients was $42.94 \pm 21.68$ months, 19 (54.3\%) were females and 16 were males $(45.7 \%)$. Of the 35 patients included in the study $29(82.9 \%)$ had the diagnosis of developmental dysplasia of hip (DDH), 4 (11.4\%) had cerebral palsy with acetabular dysplasia and $2(5.7 \%)$ had developed acetabular dysplasia secondary to septic arthritis.

The various radiological parameters showed the following patterns in the study (Table 1):

Table 1: Improvement in the mean value of acetabular index following Dega osteotomy from the preoperative period to postoperative period and at follow up.

\begin{tabular}{|c|c|c|c|c|}
\hline \multicolumn{2}{|c|}{$\begin{array}{l}\text { Acetabular index } \\
\text { in degrees }\end{array}$} & Mean \pm SD & $\begin{array}{l}\text { Min - } \\
\max \end{array}$ & P value \\
\hline \multicolumn{2}{|c|}{ Pre-operative } & $42.43 \pm 4.77$ & $35-52$ & \multirow[t]{3}{*}{$<0.001$} \\
\hline \multicolumn{2}{|c|}{ Post-operative } & $25.69 \pm 2.15$ & $20-29$ & \\
\hline \multicolumn{2}{|c|}{ At 2 years follow up } & $19.86 \pm 2.45$ & $16-26$ & \\
\hline \multicolumn{5}{|c|}{ Comparison of the $P$ values of acetabular index } \\
\hline \multicolumn{3}{|c|}{ Acetabular index } & \multicolumn{2}{|c|}{ P value } \\
\hline \multirow{2}{*}{$\begin{array}{l}\text { Pre- } \\
\text { operative }\end{array}$} & \multicolumn{2}{|c|}{ Post-operative } & \multicolumn{2}{|c|}{$<0.001$} \\
\hline & \multicolumn{2}{|c|}{ At 2 years follow up } & \multicolumn{2}{|c|}{$<0.001$} \\
\hline $\begin{array}{l}\text { Post- } \\
\text { operative }\end{array}$ & \multicolumn{2}{|c|}{ At 2 years follow up } & \multicolumn{2}{|c|}{$<0.001$} \\
\hline
\end{tabular}


The mean value of acetabular index improved from $42.43 \pm 4.77$ degrees in preoperative period to $25.69 \pm 2.15$ degrees in the postoperative period. At the follow up of 2 years, the mean value was $19.86 \pm 2.45$ degrees (Table 2).

Table 2: Improvement in the mean value of CE angle of Wiberg following Dega osteotomy from the preoperative period to postoperative period and at follow up.

\begin{tabular}{|llll|}
\hline CE angle of Wiberg in degrees & Mean \pm SD & Min - Max & P Value \\
\hline Pre-operative & $(-) 32.49 \pm 21.60$ & $(-) 60-19$ & $<0.001$ \\
\hline Post-operative & $25.46 \pm 4.58$ & $20-40$ & \\
\hline 2 Year follow up & $32.06 \pm 5.48$ & $25-45$ & P value \\
\hline Comparison of the P values of CE angle of Wiberg & & $<0.001$ \\
\hline CE angle of Wiberg & & Post-operative & $<0.001$ \\
\hline Pre-operative & & At 2 year follow up & $<0.001$ \\
\hline Post-operative & At 2 year follow up \\
\hline
\end{tabular}

Table 3: The changes in Reimer's extrusion index following the procedure.

\begin{tabular}{|c|c|c|c|c|}
\hline Reimer's extrusion index preoperative (\%) & Frequency & $\%$ & & \\
\hline 25 & 1 & $2.9 \%$ & & \\
\hline 29 & 1 & $2.9 \%$ & & \\
\hline 43 & 1 & $2.9 \%$ & & \\
\hline 50 & 1 & $2.9 \%$ & 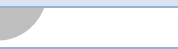 & \\
\hline 60 & 1 & $2.9 \%$ & & \\
\hline 80 & 1 & $2.9 \%$ & & \\
\hline Dislocated (100) & 29 & $82.9 \%$ & & \\
\hline Total & 35 & $100 \%$ & & \\
\hline \multicolumn{5}{|c|}{ Freqency of the values of Reimer's extrusion index in the preoperative period expressed in percentage } \\
\hline Reimer's extrusion index preoperative (\%) & $\mathbf{N} \circlearrowleft$ & Mean \pm SD & Min - Max & P Value \\
\hline Pre-operative & 35 & $91.06 \pm 21.43$ & $25-100$ & \multirow[t]{3}{*}{$<0.001$} \\
\hline Post-operative & 35 & $2.77 \pm 3.46$ & $0-18$ & \\
\hline Follow up of 2 years & 35 & $0.29 \pm 1.18$ & $0-5$ & \\
\hline
\end{tabular}

Depiction of improvement in the mean values of Reimer's extrusion index along with P values following Dega osteotomy from the preoperative period to postoperative period and at follow up.

Table 4: Changes in the continuity of Shenton's line along with P values following Dega osteotomy from the preoperative period to postoperative period and at follow up.

\begin{tabular}{|c|c|c|c|c|c|c|}
\hline \multirow[b]{2}{*}{$\begin{array}{l}\text { Shentons line } \\
\text { preoperative }\end{array}$} & Preoperative & Postoperative & $\begin{array}{l}\text { Follow up } \\
\text { of } 2 \text { years }\end{array}$ & \multicolumn{3}{|l|}{ P Value } \\
\hline & $\begin{array}{l}\text { Frequency } \\
(\%)\end{array}$ & $\begin{array}{l}\text { Frequency } \\
(\%)\end{array}$ & $\begin{array}{l}\text { Frequency } \\
(\%)\end{array}$ & $\begin{array}{l}\text { Preoperative } \\
\text { vs Post op }\end{array}$ & $\begin{array}{l}\text { Preoperative vs } \\
\text { follow up of } 2 \\
\text { years }\end{array}$ & $\begin{array}{l}\text { Post-operative } \\
\text { vs follow up } \\
\text { of } 2 \text { years }\end{array}$ \\
\hline Broken & $35(100)$ & $0(0 \%)$ & $0(0 \%)$ & \multirow{3}{*}{$<0.001$} & \multirow{3}{*}{$<0.001$} & \multirow{3}{*}{$<0.001$} \\
\hline Continous & $0(0 \%)$ & $35(100 \%)$ & $35(100 \%)$ & & & \\
\hline Total & $35(100 \%)$ & $35(100 \%)$ & $35(100 \%)$ & & & \\
\hline
\end{tabular}

The mean value of CE Angle of Wiberg improved from $32.49 \pm 21.60$ degrees in preoperative period to $25.46 \pm 4.58$ in the postoperative period. At the follow up of 2 years the mean value was $32.06 \pm 5.48$ degrees (Table $3)$.

The mean value of Reimer's Extrusion index improved from $91.06 \pm 21.43 \%$ in preoperative period to
$2.77 \pm 3.46 \%$ in the postoperative period. At the follow up of 2 years, the mean value was $0.29 \pm 1.18 \%$ (Table 4 ). The Shenton's line was broken in all the 35 patients preoperatively.

Postoperatively, and at follow up the line was continuous in all the patients. The changes in all the four parameters from preoperative period to postoperative period and at 
follow up of 2 years were statistically significant ( $p$ value<0.001) (Figure 2-5).

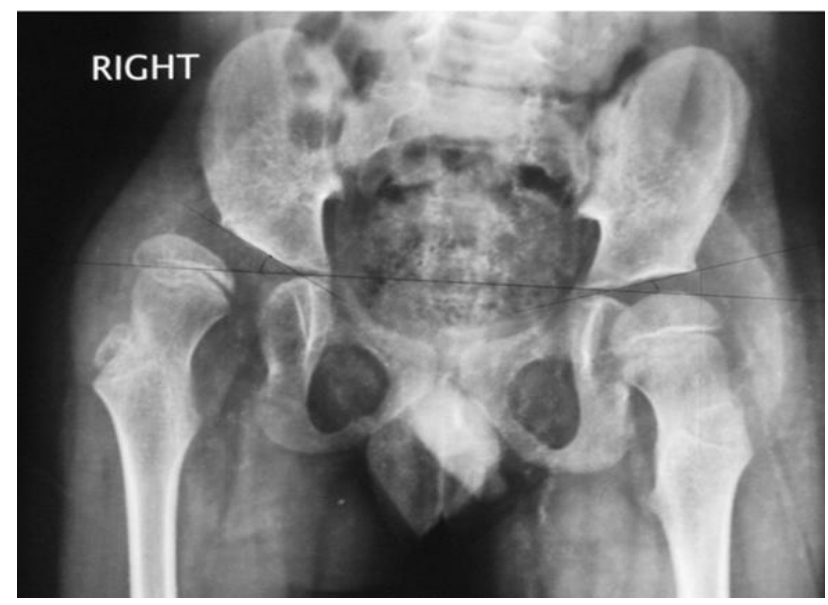

Figure 2: A case of cerebral palsy with acetabular dysplasia right hip and subluxated femoral head.

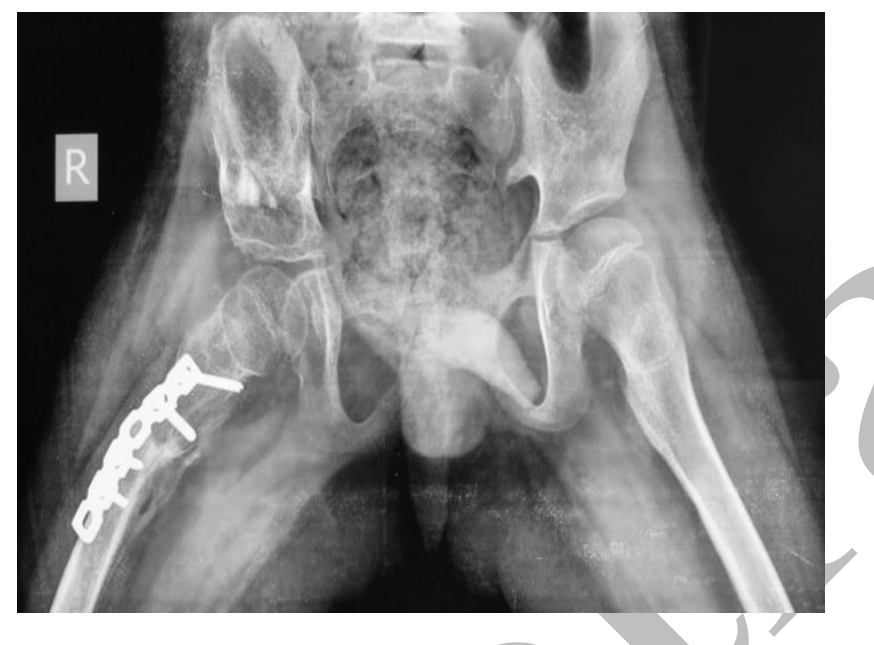

Figure 3: Follow up radiograph of the same patient following Dega osteotomy showing the well contained femoral head and corrected acetabular dysplasia.

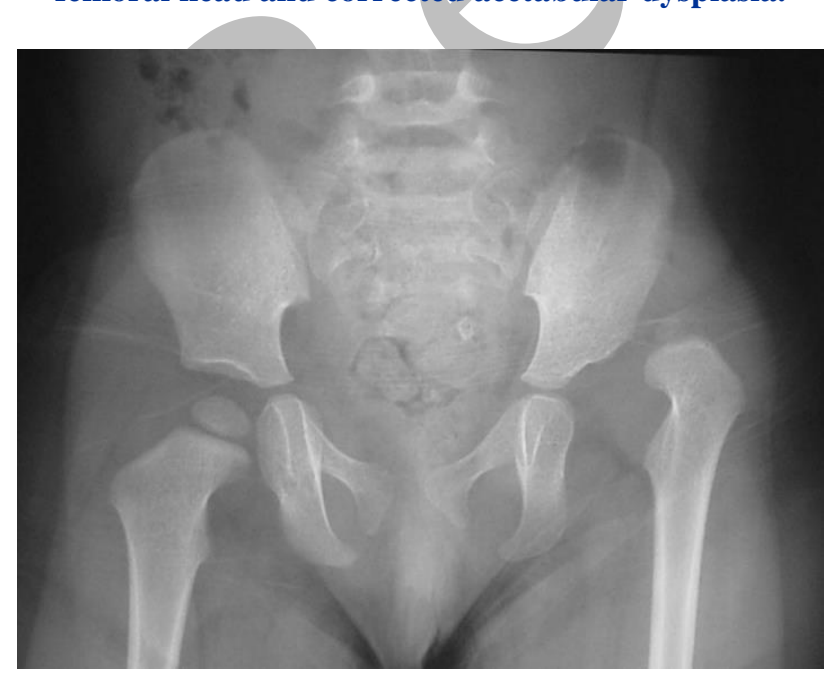

Figure 4: A case of DDH left hip with dislocated femoral head and acetabular dysplasia.

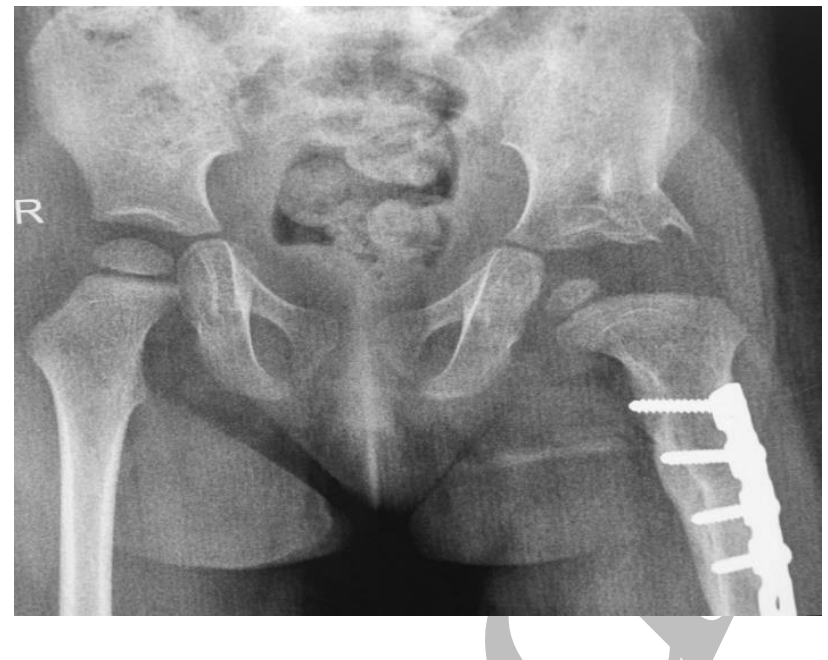

Figure 5: Follow up radiograph of the same patient following Dega osteotomy showing the well contained femoral head and corrected acetabular dysplasia.

\section{DISCUSSION}

Acetabular dysplasia is a condition defined by the inadequate development of an individual's acetabulum. This condition is an essential part of developmental dysplasia of hip (DDH). Actabular dysplasia may also occur in the absence of a frank dislocation or subluxation of the hip. It may secondarily occur in a variety of other neurological disorders such as cerebral palsy. It may also follow infection, trauma or Perthes disease. Acetabular dysplasia is one of the leading causes of hip joint osteoarthritis, particularly in women. Patients with acetabular dysplasia, who have developed symptoms around the age of 20 rarely, get beyond their early thirties without requiring total hip arthroplasty. ${ }^{1}$ So it becomes imperative to treat acetabular dysplasia when detected early in life to avoid the complications and disabilities the patient may have to encounter later in life.

The treatment of acetabular dysplasia varies according to the age of the patient. Upto 18 months, primarily conservative methods are used. Surgical techniques are used after 18 months. Various surgical techniques have been described for the correction of acetabular dysplasia with variable outcomes.

In the English-speaking world, a new osteotomy has been introduced for treatment for treatment of acetabular dysplasia. This osteotomy described by Dega, in 1969, is an incomplete transiliac osteotomy of the anterior and middle portions of the inner cortex of the ilium, leaving an intact hinge posteriorly consisting of the intact posteromedial iliac cortex and sciatic notch, taking advantage of the inherent flexibility of the triradiate cartilage and surrounding bone in the pelvis of young children to reshape the acetabulum. ${ }^{12,19}$ One of the advantages of this procedure over the others is that it does not require placement of hardware to obtain the desired coverage of femoral head. The osteotomy is kept open by placing bone grafts. These can be obtained from the 
patient's femur in the event of concomitant femoral osteotomy or the artificial bone graft can be used. No internal fixation is required and thus the need for a second general anaesthetic procedure for implant removal is eliminated. The procedure does not cause limb length discrepancy.

In present study, we evaluated the effectiveness of Dega osteotomy, in achieving correction of acetabular dysplasia in children. We evaluated the correction by measurement of various radiological parameters, namely, the Acetabular Index, Center Edge angle of Wiberg, the Reimer's Extrusion index, and Shenton's line. The patients with a diagnosis of DDH and cerebral palsy underwent a concomitant femoral procedure in the form of varus derotational osteotomy and arthroscopic hip debridement. This prospective observational study was carried out on 35 patients in the age range of 18 months to 8 years with mean age of $42.94 \pm 21.68$ months. In our study sample of 35 cases, 29 had DDH, 4 were secondary to cerebral palsy and 2 had developed dysplasia following septic arthritis of the hip. Since most the patients (29 out of $35,82.9 \%$ ) included in this study had the diagnosis of $\mathrm{DDH}$, the results of this study are more representative of dysplasia associated with DDH. In present study we evaluated the correction of acetabular dysplasia by measuring the change in four radiological parameters namely, Acetabular Index, Centre Edge Angle of Wiberg, Reimer's Extrusion Index and Shenton's line. The evaluation was carried out on standard antero-posterior radiographs of the pelvis done preoperatively, 48 hours postoperatively and at a follow up of 2 years. All the values showed considerable improvement and were in normal ranges postoperatively and at follow up (Tables 14 and Figures 2-5). This was statistically highly significant ( $p$ value $<0.001$ ). The results of present study are quite comparable to the other studies done about this procedure. ${ }^{19-21}$

There were no major complications in present patients at 2 year follow up, with no deep infections or neurovascular injury. Two patients were found to have significant hip stiffness when the hip spica was removed. In both these cases, there was a slow improvement in the hip range of motion with time. Both the children needed physiotherapy to help with gaining hip range, especially adduction. All the patients were progressing well with normal clinical and radiological features and are expected to have a normal or a near normal functional outcome when they reach adulthood.

\section{CONCLUSION}

From the above analysis, it is clear that the Dega osteotomy is highly effective in the surgical treatment of acetabular dysplasia. The correction in the acetabular index is excellent and the improvement in the CE angle, the Extrusion Index, and the Shenton's line reflect the overall effectiveness of the surgery to contain the hip. Thus, from our study we can infer that Dega osteotomy is a safe, effective and versatile surgical procedure for the treatment of acetabular dysplasia secondary to DDH and other disorders.

\section{Funding: No funding sources}

Conflict of interest: None declared

Ethical approval: The study was approved by the Institutional Ethics Committee

\section{REFERENCES}

1. Kosuge D, Yamada N, Azegami S, Achan P, Ramachandran M. Management of developmental dysplasia of the hip in young adults: current concepts. Bone Joint J. 2013;95(6):732-7.

2. Salter RB. Role of innominate osteotomy in the treatment of congenital dislocation and subluxation of the hip in the older child. J Bone Joint Surg Am. 1966; 48:1413-39.

3. Wedge JH. Hip joint acetabular dysplasia. J Pediatr Orthop. 1997;17(2):141-2.

4. Salter RB. Innominate osteotomy in the treatment of congenital dislocation and subluxation of the hip joint. J Bone Joint Surg Br. 1961;43(3):518-39.

5. Sutherland DH, Greenfield R. Double innominate osteotomy. J Bone Joint Surg Am. 1977;59(8):108291.

6. Steel HH. Triple osteotomy of the innominate bone. J Bone Joint Surg Am. 1973;55(2):343-50.

7. Tonnis D, Behrens K, Tscharani F. A modified technique of the triple pelvic osteotomy: early results. J Pediatr Orthop. 1981;1(3):241-9.

8. Pemberton PA. Pericapsular osteotomy of the ilium for treatment of congenital subluxation and dislocation of the hip. J Bone Joint Surg Am. 1965;47:65-86.

9. Mubarak SJ, Valencia FG, Wenger DR. One-stage correction of the spastic dislocated hip. Use of pericapsular acetabuloplasty to improve coverage. J Bone Joint Surg Am. 1992;74(9):1347-57.

10. Chung CY, Choi IH, Cho TJ, Yoo WJ, Lee SH, Park MS. Morphometric changes in the acetabulum after Dega osteotomy in patients with cerebral palsy. J Bone Joint Surg Br. 2008;90(1):88-91.

11. Ozgur AF, Aksoy MC, Kandemir U, Karcaaltncaba M, Aydinqoz M, Yazici $M$, et al. Does Dega osteotomy increase acetabular volume in developmental dysplasia of hip? J Pediatr Orthrop B. 2006;15(2):83-6.

12. Dega W. Selection of surgical methods in the treatment of congenital dislocation of the hip in children. Chir Narzadow Ruchu Ortop Pol. 1969;34(3):357-66.

13. Tonnis D. Normal values of the hip joint for the evaluation of X-rays in children and adults. Clin Orthop Relat Res.1976;119:39-47.

14. Pederson DR, Lamb CA, Dolan LA, Ralston HM, Weinstein SL, Morcuende JA. Radiographic measurements in developmental dysplasia of the 
hip:reliability and validity of a digitizing program. J Pediatr Orthop. 2004;24(2):156-60.

15. Pirpiris M, Payaman KR, Otsuka NY. The assessment of acetabular index:is there still a place for plain radiography. $\mathrm{J}$ Pediatr Orthop. 2006;26(3):310-5.

16. Tudor A, Dalen L, Dugan R, Tomislav P, Ratko S. Prognostic value of refined Wiberg's angle in hip development. Coll Antropol. 2005;29(1):267-70.

17. Beals RK. Developmental changes in the femur and acetabulum in spastic paraplegia and diplegia. Dev Med Child Neurol. 1969;11:303-13.

18. Jones DH. Shenton's line. J Bone Joint Surg Br. 2010;92(9):1312-5.

19. Karlen JW, Skaggs DL, Ramachandran M, Kay RM. The Dega osteotomy: a versatile osteotomy in the treatment of developmental and neuromuscular hip pathology. J Pediatr Orthop. 2009;29(7):676-82.

20. Al-Ghamdi A, Rendon JS, Al-Faya F, Saran N, Benaroch T, Hamdy RC. Dega osteotomy for the correction of acetabular dysplasia of the hip: a radiographic review of 21 cases. J Pediatr Orthop. 2012;32(2):113-20.

21. Akgul T, Bora Goksan S, Biligili F, Valiyev N, Hurmeydan OM. Radiological results of modified Dega osteotomy in Tonnis grade 3 and 4 developmental dysplasia of the hip. J Pediatr Orthop B. 2014;23(4):333-8.

Cite this article as: Jan WF, Sarup S, Dar MY, Jahan A, Khan ON. Observations on radiological correction of acetabular dysplasia by Dega transiliac osteotomy. Int J Res Med Sci 2017;5:1991-7.

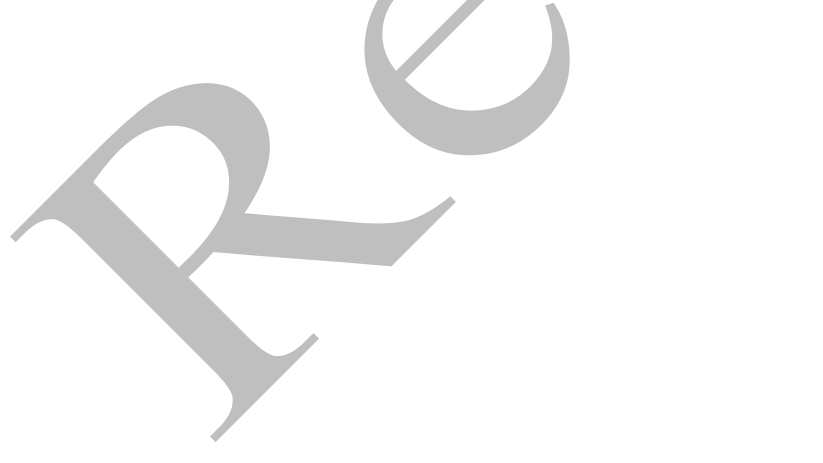

